\section{Feeding Preference of Melon Thrips on Orchids in Hawaii}

\author{
Trent Y. Hata', Arnold H. Hara', and James D. Hansen ${ }^{3}$ \\ Department of Entomology, University of Hawaii at Manoa, 461 West \\ Lanikaula Street, Hilo, HI 96720
}

Additional index words. dendrobium, host preference, Thrips palmi

\begin{abstract}
Feeding preference of melon thrips, Thrips palmi Karny (Thysanoptera: Thripidae) was evaluated on 21 Dendrobium cultivars and the bamboo orchid Arundina graminifolia (D. Don) Hochr. Pigmented flowers resembling the morphotype phalaenopsis from Phalaenanthe sections were preferred over nonpigmented phalaenopsis, Phalaenanthe $\times$ Ceratobium hybrids, and bamboo orchids. This study suggests the separation of susceptible cultivars from preferred cultivars as a pest management strategy for melon thrips control.
\end{abstract}

A serious quarantine pest of dendrobium is the melon thrips, Thrips palmi, which is widely distributed throughout southeast Asia and several islands in the Pacific, including Hawaii (Johnson, 1986). Melon thrips has a wide host range, affecting many crops of economic importance (Johnson, 1986). Adults and nymphs are reported to feed on various plant parts such as leaves, stems, flowers, and fruits, causing scars and deformities. In severe infestations, plant death has been reported (Sakimura et al., 1986).

On dendrobium, adult melon thrips and nymphs are found in open blooms deep within the flower and petal folds. Flower injury is observed with severe infestations. Light infestations produce no visible injury and, therefore, are difficult to detect. Melon thrips is a difficult pest to control with insecticides due to physical protection of the thrips by flower petals. Additionally, melon thrips tolerate many organophosphate insecticides (Suzuki et al., 1982).

Melon thrips is a federal quarantine action pest with a zero tolerance level (P.Y. Lai, unpublished). Orchid flower shipments to the continental United States and other uninfested areas of the world are rejected as a result of melon thrips infestations (Nakahara, 1985). Development of management strategies that decrease the likelihood of $\mathrm{T}$. palmi infestations would aid the orchid industry in the export of dendrobiums. The objectives of this study were to determine

Received for publication 21 Dec. 1990. Journal Series no. 3546, the Hawaii Institute of Tropical Agriculture and Human Resources. We gratefully acknowledge E. Notley for technical assistance and dendrobium farms in Hilo, Puna, and Kona, Hawaii, for their cooperation. Reference to a company or product name does not imply approval or recommendation of the product by the College of Tropical Agriculture and Human Resources, Univ. of Hawaii, or the U.S. Dept. of Agriculture to the exclusion of others that may be suitable. The cost of publishing this paper was defrayed in part by the payment of page charges. Under postal regulations, this paper therefore must be hereby marked advertisement solely to indicate this fact.

'Research Associate.

${ }^{2}$ Associate Entomologist.

${ }^{3}$ Assistant Researcher. the feeding preference of $T$. palmi on various dendrobium cultivars and determine if the bamboo orchid found in the wild is a source of thrips.

Infestation preference in shadehouse. (Study 1). Fourteen dendrobium cultivars were grown in a volcanic cinder medium under $30 \%$ shade using standard cultural practices in Kapoho, Hawaii. Thirty plants of each cultivar were divided into two equal groups and placed on separate benches in a thripsinfested shadehouse. Thrips population was allowed to build for 3 weeks before the survey. The thrips population for each group was surveyed weekly for 5 weeks from 15 flowers of each cultivar. Two groups, each containing 15 flowers, were also taken weekly from bamboo orchids growing in the wild outside the shadehouse. Thrips were extracted with a Berlese funnel, and nymphs counted under a dissecting microscope. Nymphs for identification were reared on eggplant, Solarium melongena L. var. Esculentum. To evaluate feeding in less susceptible cultivars, which otherwise may not be observed, a nymph population of $\mathrm{N}=150$ per group was the minimum total population level for determining feeding preference among the cultivars. Thrips population data
wWild bamboo orchid, Arundina graminifolia. among the cultivars were analyzed by Kruskall-Wallis nonparametric test. A dendrogram was produced using Ward's minimum variance method of cluster analysis (SAS Institute, 1987). In addition, flower color and morphotype were subjected to single degreeof-freedom comparisons.

Field survey of infestation (Study 2). Seven cultivars from three commercial dendrobium farms located in Hilo, Puna, and Kaihua-Kona, Hawaii, were surveyed for T. palmi. Plants at all three farms were grown in crushed basaltic rock under $30 \%$ shade. Four samples, each containing 15 flowers, were randomly selected from each cultivar. Thrips were extracted with a Berlese funnel and counted under a dissecting microscope. At Hilo and Kailua-Kona farms, thrips populations among cultivars were subjected to Hartley's Fmax test for homogeneity. Data were subjected to analysis of variance and means separated by Duncan-Wailer K-ratio $t$ test.

All nymphs isolated in Study 1 were identified as T. palmi. Four of the weekly surveys had the minimum population levels to determine feeding preference. The number of nymphs differed significantly among the cultivars $(P<0.001)$. Thrips were not found on bamboo orchid, and the Ceratobium-type orchids had the fewest among the cultivars
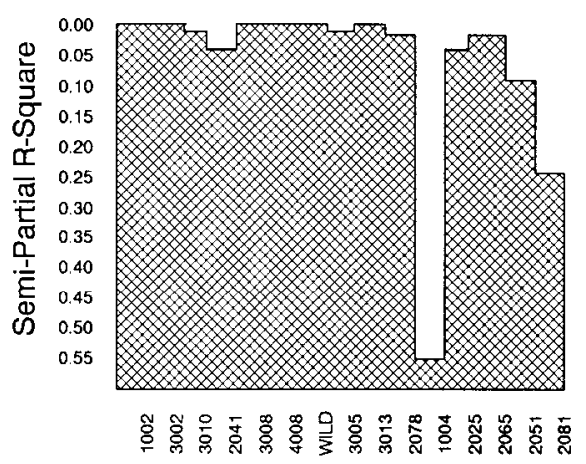
Cultivar

Fig. 1. Cluster analysis of number of Thrips palmi nymphs by Ward's minimum variance method. Cultivars 1004, 2025, 2065, 2051, and 2081 were preferred over others.

Table 1. Average number of Thrips palmi nymphs per cultivar from four weekly surveys.

\begin{tabular}{|c|c|c|c|}
\hline Cultivar & Type $^{z}$ & Color ${ }^{y}$ & Nymphs $s^{x}$ \\
\hline 2081 Chieko Matsui x Kelli Nicole & $\mathbf{P}$ & DP & 65.8 \\
\hline 2051 Dorian Sato X Kristen Ann & $P$ & DP & 36.3 \\
\hline 2065 Phalaenopsis $\times$ June Carson & $\mathrm{P}$ & $\mathrm{P}$ & 23.5 \\
\hline 2025 Dorian Sato x G. Kur-L. Ham & $\mathrm{P}$ & DP & 22.5 \\
\hline 1004 Phalaenopsis Alba $\times$ Self & $\mathrm{P}$ & LW & 20.3 \\
\hline $\mathrm{H} 3010$ & C & DP & 10.0 \\
\hline 2078 Joan Kushima & SP & PB & 8.3 \\
\hline 1002 Phalaenopsis Alba $\times$ Sibling & $\mathrm{P}$ & W & 7.3 \\
\hline 3002 Barry Fujimoto $x$ Jaquelyn Thomas & $\mathrm{C}$ & DP & 5.0 \\
\hline 3005 Madam Julie Sulianti & $\mathrm{C}$ & LW & 4.5 \\
\hline 3013 Singapore White & $\mathrm{C}$ & W & 3.8 \\
\hline 2041 Joan Kushima & SP & DL & 3.0 \\
\hline 3008 Jaquelyn Thomas $\times 44 \times 503$ & $\mathrm{C}$ & $\mathrm{LW}$ & 0.5 \\
\hline 4008 Robson Waimea $x$ May Neal SRPN & $\mathrm{C}$ & YC & 0.3 \\
\hline Wild bamboo orchid ${ }^{w}$ & ... & WL & 0.0 \\
\hline
\end{tabular}

${ }^{\mathrm{x}}$ Morphotype: $\mathrm{P}=$ Phalaenanthe type, $\mathrm{C}=$ Ceratobium type, $\mathrm{SP}=$ Semiphalaenopsis.

yDP = Deep purple; $P=$ purple; $L W=$ lavender white; $W=$ white; $P B=$ pink blush; $D L=$ deep lavender; $\mathrm{YC}=$ yellow with chocolate center; $\mathrm{WL}=$ white and lavender.

×Significant by Kruskall-Wallis nonparametric test, $P<0.001$; mean of 15 flowers. 
Table 2. Flower color and morphotype preference of Thrips palmi. ${ }^{2}$

\begin{tabular}{|c|c|}
\hline Color & $P>\mathrm{F}$ \\
\hline $\begin{array}{l}\text { Purple and lavender/pink vs. white } \\
\text { and yellow }\end{array}$ & $0.0204^{*}$ \\
\hline Purple vs. lavender/pink & $0.0001^{*}$ \\
\hline White vs. yellow & 0.6163 \\
\hline Morphotype & \\
\hline $\begin{array}{l}\text { Phalaenanthe vs. semiphalaenop- } \\
\text { sis, Ceratobium and Wild }\end{array}$ & $0.0001^{*}$ \\
\hline $\begin{array}{l}\text { Wild vs. semiphalaenopsis and } \\
\text { Ceratobium }\end{array}$ & 0.5737 \\
\hline Semiphalaenopsis vs. Ceratobium & 0.8013 \\
\hline
\end{tabular}

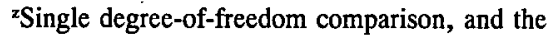
corresponding probability of significance.

(Table 1). The Phalaenanthe types had the most thrips. Cluster analysis clearly separated preferred cultivars from less preferred (Fig. 1). Single degree-of-freedom comparisons indicated purple, lavender/pink orchids, and Phalaenanthe morphotype were more attractive than other colors and morphotypes (Table 2). Based on this study, purple, lavender, and pink flowers resembling the morphotype phalenopsis from Phalaenanthe sections were preferred over nonpigmented phalenopsis and Ceratobium $\times$ Phalaenanthe hybrids. In addition, pigmented Ceratobium morphotype orchids were more attractive than nonpigmented.

Surveys of dendrobium farms in Study 2 were consistent with results of Study 1. At the Hilo farm, dark purple semiphalaenopsis morphotype had the most thrips $(P=0.01)$. Pigmented Ceratobium morphotype orchids were more attractive than nonpigmented. At the Puna farm, dark purple Phalaenanthe morphotype had the most thrips. Ceratobium morphotype orchids were not attractive to $T$. palmi. At the Kailua-Kona farm, pigmented semiphalaenopsis morphotype attracted the most thrips $(P<0.01)$. Pigmented Ceratobium morphotypes were more attractive than nonpigmented (Table 3 ).

For pest management of melon thrips, purple, lavender, and pink orchids of the Phalaenanthe morphotype should be isolated from the nonpreferred cultivars to reduce thrips population near the latter. This cultural practice will also reduce the number of pesticide applications and minimize the risk of melon thrips developing insecticide resistance. In addition, by surveying susceptible cultivars, dendrobium growers would be able to control thrips by early detection and immediately implement a spray program reducing rejection in shipment. This study also suggests bamboo orchids growing in the wild outside of shadehouses are not hosts of $T$. palmi.

\section{Literature Cited}

Johnson, M. 1986. Population trends of a newly introduced species, Thrips palmi (Thysanoptera: Thripidae), on commercial watermelon plantings in Hawaii. J. Econ. Entomol. 79:718-720.

Nakahara, L.M. 1985. Thrips palmi on dendrobium. Proc. 1985 Hawaii Commercial Dendrobium Growers Conf., Coop. Ext. Serv., Univ. of Hawaii. p. 29-31.

Sakimura, K., L.M. Nakahara, and H.A. Den-

Table 3. Average number of T. palmi per 15 flowers from dendrobium farms in Hilo, Puna, and Kona, Hawaii. ${ }^{2}$

\begin{tabular}{|c|c|c|c|c|c|}
\hline Cultivar & Typey & Color $^{x}$ & Hilow $^{w}$ & Punav $^{v}$ & Kona $^{4}$ \\
\hline Tay Swccking & $\mathbf{P}$ & $\mathrm{DP}$ & $\cdots$ & 3.5 & --- \\
\hline Dendrobium cross ${ }^{t}$ & $\mathbf{P}$ & LW & - & --- & $16.8 \mathrm{a}$ \\
\hline Nancy Reagan & SP & DP & $3.5 \mathrm{a}$ & --- & $-\cdots$ \\
\hline Uniwai Blush & $\mathrm{C}$ & PB & $0.8 \mathrm{~b}$ & --- & $4.8 \mathrm{~b}$ \\
\hline Uniwai Supreme & $\mathrm{C}$ & TTL & $0.5 \mathrm{~b}$ & 0.0 & $6.3 \mathrm{~b}$ \\
\hline Uniwai Princess & $\mathrm{C}$ & LL & $0.0 \mathrm{~b}$ & $\cdots$ & ... \\
\hline Uniwai Pearl & $\mathrm{C}$ & $\mathrm{W}$ & $0.0 \mathrm{~b}$ & 0.3 & $2.5 \mathrm{~b}$ \\
\hline
\end{tabular}

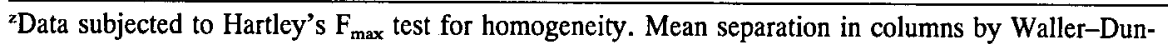
can K-ratio $t$ test.

Morphotype: $\mathrm{P}=$ Phalaenanthe type, $\mathrm{C}=$ Ccratobium type, $\mathrm{SP}=$ Semiphalaenopsis.

${ }^{\mathrm{DP}}=$ Dark purple; $\mathrm{PB}=$ pink blush; TTL = two-tone lavender; $\mathrm{LL}=$ light lavender; $\mathrm{LW}=$ lavender white; $\mathrm{W}=$ white.

wData transformed to $\mathrm{x}+1$ and subjected to ANOVA, $\boldsymbol{P}=0.01$.

vo analysis was conducted for survey in Puna.

unniwai Pearl variance was not homogeneous by Hartley's $\mathrm{F}_{\max }$ test.

'Dendrobium neo Hawaii $4 \mathrm{~N} \times$ Phalaenopsis alba ' $\mathrm{C}$ '.

mark. 1986. A Thrips, Thrips palmi Karny (Thysanoptera: Thripidae). Fla. Dept. Agr. \& Consumer Serv., Div. of Plant Ind., Entomol. Circ. 280.

SAS Institute Inc. 1987. SAS/STAT guide for per- sonal computers, Version 6 (cd.). SAS Institute, Inc., Cary, N.C.

Suzuki, H., S. Tamaki, and A. Miyara. 1982. Physical control of Thrips palmi Karny. Proc. Assn. Plant Protection Kyushu 28:134-137. 